\title{
Acute urethritis due to Neisseria meningitidis group A acquired by orogenital contact: case report
}

\author{
A P R WILSON,* J WOLFF,* W ATIA $\dagger$ \\ From the Departments of *Microbiology, Whittington Hospital, and $\dagger$ Genitourinary Medicine, Royal Northern \\ Hospital, London
}

SUMMARY A case of heterosexual transmission of Neisseria meningitidis group A by fellatio, which resulted in acute purulent urethritis in the male partner, is presented. The emotional impact of a mistaken diagnosis of gonococcal infection and the need to treat asymptomatic throat carriage in sexual contacts makes early recognition of meningococcal infection important in this unusual circumstance.

Although first described in $1942,{ }^{1}$ most reports of purulent urethritis caused by Neisseria meningitidis have only appeared since $1974 .^{2-10}$ In $5 \%$ to $10 \%$ of the population the organism is carried in the pharynx without symptoms, " and anogenital transmission is possible in homosexual men. ${ }^{12}{ }^{13}$ There have, however, been only three previous reports of probable heterosexual transmission of $N$ meningitidis by orogenital contact. $^{8-10}$

\section{Case report}

A man aged 18 attended the department of genitourinary medicine of the Royal Northern Hospital, London on the 6 December 1982 with a five day history of dysuria and urethral discharge. He had a stable heterosexual relationship and denied having had other recent sexual contacts. Sexual intercourse had last occurred two weeks previously. On examination, he had a thick purulent discharge, which showed Gram negative intracellular diplococci on microscopy. The patient was told that the probable diagnosis was gonococcal infection, and he was treated with a single oral dose of ampicillin $3 \mathrm{~g}$ and probenecid $1 \mathrm{~g}$. He accused his 19 year old girlfriend of unfaithfullness, but persuaded her to attend the next day. She was asymptomatic and denied having had other sexual partners. Specimens were taken from her urethra, cervix, and rectum, but not her throat. Though Gram staining gave negative results, she was also given

Address for reprints: Dr A P R Wilson, Department of Microbiology, Whittington Hospital, Highgate Hill, London N19 5NF

Accepted for publication 24 July 1988 ampicillin and probenecid pending receipt of her culture results.

$N$ gonorrhoeae was not isolated from the patient or his girlfriend, but a heavy growth of $\mathrm{N}$ meningitidis was obtained from the urethral discharge of the man.

When the man attended for follow up four days later, he was free of symptoms, his urethra was dry, and urethral and throat cultures gave negative results. The two glass urine test was clear in both specimens. Both partners returned to the clinic on 14 December. They were still without symptoms, and a urethral culture from the man and urethral and cervical cultures from the woman gave negative results, but a throat swab from the woman produced a heavy growth of $N$ meningitidis. On 22 December, she started taking a course of cotrimoxazole, two $280 \mathrm{mg}$ tablets twice a day. No Neisseria spp were isolated from a further throat swab taken on the 4 January 1983. At her final attendance on 15 February, she reported that she and her boyfriend were asymptomatic and had resumed normal relations. Smears and cultures from her urethra and cervix remained negative.

The isolates from the urethra of the man and the throat of the woman were confirmed by the Meningococcal Reference Laboratory, Withington Hospital, Manchester, and by the Venereal Diseases Reference Laboratory, London Hospital, as being $N$ meningitidis group $A$. The urethral isolate was found to require concentrations of $200 \mathrm{mg} / 1$ sodium sulphadiazine, 0.02 $\mathrm{mg} / \mathrm{l}$ benzyl penicillin, and $0.25 \mathrm{mg} / \mathrm{l}$ rifampicin to inhibit its growth. The minimum inhibitory concentration (MICs) for the throat isolate were $100 \mathrm{mg} / \mathrm{l}$ sodium sulphadiazine, $0.02 \mathrm{mg} / \mathrm{l}$ benzyl penicillin, and $0 \cdot 125 \mathrm{mg} / \mathrm{l}$ rifampicin.

In the subsequent year $N$ meningitidis was isolated 
from the pharynx of 28 men and three women attending the department of genitourinary medicine. Sixteen isolates were not groupable, nine were of group B, three of group C, and one each of groups X, $Z$, and $Z / 29 E$. No other organisms of group $A$ were encountered. No further cases of orogenital transmission of $N$ meningitidis have been noted at this hospital to date.

\section{Discussion}

The presence of $N$ meningitidis group A on the smear and in culture, the rapid clinical response to ampicillin, and the absence of non-specific urethritis after treatment suggested that the organism had caused the acute urethritis of the patient. The organism was probably acquired from the throat of the female partner by orogenital contact, which had taken place two weeks before the onset of symptoms. The two strains had similar antibiotic sensitivity patterns and were unusually of serogroup A. With the possible exception of a single "anogenital" isolate reported by Judson $e t$ $a l,{ }^{4}$ organisms of this group in patients with urethritis have not been reported since Carpenter and Charles did so in 1942. ${ }^{1}$ Organisms of serogroup A were not found in throat swabs from a series of 414 military staff, despite a $64 \%$ incidence of meningococci. ${ }^{14}$

Beck et al isolated $N$ meningitidis group B from the urethral discharge of a man and the pharynx of his female sexual partner after they had had orogenital intercourse. ${ }^{10}$ Karolus et al reported $N$ meningitidis group $\mathrm{Z}$ in similar circumstances. ${ }^{9}$ Talbot and Collins reported a case of probable orogenital transmission, but were unable to group the organisms and did not state whether fellatio had taken place. ${ }^{8}$ A male chimpanzee was also assumed to have infected itself by frequently engaging in self contact. ${ }^{15}$

Asymptomatic urethral carriage of $\mathrm{N}$ meningitidis in men is rare, only nine cases (four of which were in homosexual men) having been detected at a venereal disease clinic during a two year period. ${ }^{6}$ Other workers have examined urethral carriage rates, but in the homosexual, rather than heterosexual, population. In 383 patients examined by Salit and Frasch, meningococci were isolated from the throats of 129 men but from the urethra of only one. ${ }^{12}$ Janda et al reported positive cultures from the urethra of six of 815 homosexual men, of whom five had purulent urethritis. ${ }^{13}$

In the case reported here the preliminary diagnosis of gonococcal infection unnecessarily threatened a stable relationship. To prevent the recurrence of infection, sexual contacts of patients with menin- gococcal urethritis should be screened and treated as for gonococcal disease. Pharyngeal carriage of meningococci is so widespread, however, that isolates should be shown to be of the same serogroup before being considered as being possibly important. Diagnosis in this case was delayed, as no throat swab was obtained from the woman at her first presentation. The rarity of serogroup $\mathbf{A}$ indicates that orogenital transmission took place, and raises the question of whether the sexual partners of patients with other forms of meningococcal disease should be investigated.

We thank Dr D M Jones of the Public Health Laboratory, Withington Hospital, Manchester, and Dr N A Johnston of the Venereal Diseases Reference Laboratory for their help in identifying the organisms.

\section{References}

1 Carpenter $\mathbf{C M}$, Charles R. Isolation of meningococcus from the genitourinary tract of seven patients. Am J Public Health 1942; 32:640-3.

2 Faur YC, Weisburd MH, Wilson ME. Isolation of Neisseria meningitidis from the genitourinary tract and anal canal. J Clin Microbiol 1975;2:178-82.

3 Miller MA, Millikin P, Griffin PS, Sexton RA, Yousef M. Neisseria meningitidis urethritis: a case report. JAMA 1979;242: 1656-7.

4 Judson FN, Ehret JM, Eickhoff TC. Anogenital infection with Neisseria meningitidis in homosexual men. J Infect Dis 1978;137: 458-63.

5 Blackwell C, Young H, Bain SSR. Isolation of Neisseria meningitidis and Neisseria catarrhalis from the genitourinary tract and anal canal. British Journal of Venereal Diseases 1978;54:41-4.

6 Givan KF, Thomas BW, Johnston AG. Isolation of Neisseria meningitidis from the urethra, cervix, and anal canal: further observations. British Journal of Venereal Diseases 1977;53: 109-12.

7 William DC, Felman YM, Corsaro MC. Neisseria meningitidis: probable pathogen in two related cases of urethritis, epididymitis and acute pelvic inflammatory disease. JAMA 1979;242:1653-4.

8 Talbot MD, Collins BN. Presumed sexual transmission of meningococci. J Infect 1981;3:273-6.

9 Karolus JJ, Gandelman AL, Nolan BA. Urethritis caused by Neisseria meningitidis. J Clin Microbiol 1980;12:284-5.

10 Beck A, Fluker JL, Platt DJ. Neisseria meningitidis in urogenital infection. British Journal of Venereal Diseases 1974;50:367-9.

11 Greenfield S, Sheehe PR, Feldman HA. Meningococcal carriage in a population of "normal" families. J Infect Dis 1971;123:67-73.

12 Salit IE, Frasch CE. Seroepidemiologic aspects of Neisseria meningitidis in homosexual men. Can Med Assoc J 1982;126: $38-41$.

13 Janda WM, Bohnhoff M, Morello JA, Lerner SA. Prevalence and site-pathogen studies of Neisseria meningitidis and $N$ gonorrhoeae in homosexual men. JAMA 1980;244:2060-4.

14 Craven DE, Frasch CE, Mocca LF, Rose FB, Gonzalez R. Rapid serogroup identification of Neisseria meningitidis by using antiserum agar: prevalence of serotypes in a disease-free military population. J Clin Microbiol 1979;10:302-7.

15 Brown WJ, Kraus SJ, Arko RJ. Chimpanzee urethral meningococci. British Journal of Venereal Diseases 1973;49:88. 